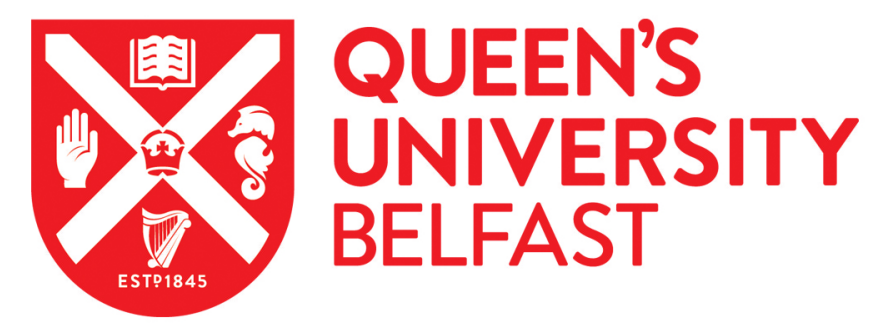

\title{
Detectability of bovine TB using the tuberculin skin test does not vary significantly according to pathogen genotype within Northern Ireland
}

Wright, D. M., Allen, A. R., Mallon, T. R., McDowell, S. W. J., Bishop, S. C., Glass, E. J., Bermingham, M. L., Woolliams, J. A., \& Skuce, R. A. (2013). Detectability of bovine TB using the tuberculin skin test does not vary significantly according to pathogen genotype within Northern Ireland. Infection, Genetics and Evolution, 19, 1522. https://doi.org/10.1016/j.meegid.2013.05.011

Published in:

Infection, Genetics and Evolution

Document Version:

Peer reviewed version

Queen's University Belfast - Research Portal:

Link to publication record in Queen's University Belfast Research Portal

Publisher rights

(c) 2015, Elsevier. Licensed under the Creative Commons Attribution-NonCommercial-NoDerivatives 4.0 International

$\mathrm{http}: / /$ creativecommons.org/licenses/by-nc-nd/4.0/ which permits distribution and reproduction for non-commercial purposes, provided the author and source are cited.

\section{General rights}

Copyright for the publications made accessible via the Queen's University Belfast Research Portal is retained by the author(s) and / or other copyright owners and it is a condition of accessing these publications that users recognise and abide by the legal requirements associated with these rights.

Take down policy

The Research Portal is Queen's institutional repository that provides access to Queen's research output. Every effort has been made to ensure that content in the Research Portal does not infringe any person's rights, or applicable UK laws. If you discover content in the Research Portal that you believe breaches copyright or violates any law, please contact openaccess@qub.ac.uk. 


\section{Detectability of bovine TB using the tuberculin skin test does}

\section{not vary significantly according to pathogen genotype within}

\section{Northern Ireland}

David M. Wright ${ }^{1 *}$, Adrian R. Allen ${ }^{2}$, Thomas R. Mallon ${ }^{2}$, Stanley W. J. McDowell ${ }^{2}$, Stephen C. Bishop ${ }^{3}$, Elizabeth J. Glass ${ }^{3}$, Mairead L. Bermingham ${ }^{3}$, John A. Woolliams ${ }^{3}$, Robin A. Skuce ${ }^{1,2}$

${ }^{1}$ School of Biological Sciences, Queen's University Belfast, 97 Lisburn Road, Belfast, BT9 7BL, UK ${ }^{2}$ Veterinary Sciences Division, Bacteriology Branch, Agri-Food and Biosciences Institute, Stormont, Stoney Road, Belfast BT4 3SD, UK

${ }^{3}$ The Roslin Institute and Royal (Dick) School of Veterinary Studies, University of Edinburgh, Easter Bush, Midlothian, EH25 9RG UK

* Corresponding author: Tel.: +44 2890632720 Email: david.m.wright@cantab.net

Present address: Centre for Public Health, Institute of Clinical Sciences - Block B, Queen's University Belfast, Royal Victoria Hospital, Grosvenor Road, Belfast, BT12 6BA, UK

Keywords: bovine tuberculosis; cattle; detectability; Mycobacterium bovis; tuberculin test.

\footnotetext{
Abstract

Strains of many infectious diseases differ in parameters that influence epidemic spread, for example virulence, transmissibility, detectability and host specificity. Knowledge of inter-strain variation can be exploited to improve management and decrease disease incidence. Bovine tuberculosis (bTB) is increasingly prevalent among farmed cattle in the UK, exerting a heavy economic burden on the
} 
farming industry and government. We aimed to determine whether strains of Mycobacterium bovis (the causative agent of bTB) identified and classified using genetic markers (spoligotyping and multilocus VNTR analysis) varied in response to the tuberculin skin test; this being the primary method of bTB detection used in the UK. Inter-strain variation in detectability of $M$. bovis could have important implications for disease control. The skin test is based on a differential delayed type hypersensitivity (DTH) response to intradermal injections of purified protein derivative (PPD) from M. bovis (PPD-B) and Mycobacterium avium (PPD-A). We searched for an association between skin test response (PPD-B skin rise minus PPD-A skin rise) and $M$. bovis genotype at the disclosing test in cultureconfirmed cases using a field dataset consisting of 21,000 isolates belonging to 63 genotypes of $M$. bovis from cattle in Northern Ireland. We found no substantial variation among genotypes (estimated responses clustered tightly around the mean) controlling for animal sex, breed and test effects. We also estimated the ratio of skin test detected to undetected cases (i.e. cases only detected at abattoir). The skin test detection ratio varied among abattoirs with some detecting a greater proportion of cases than others but this variation was unrelated to the community composition of genotypes within each abattoir catchment. These two lines of evidence indicate that M. bovis genotypes in Northern Ireland have similar detectability using the skin test.

\section{Introduction}

Many human and animal pathogens are classified into distinct strains based on genotype, virulence, immunogenicity, detectability, host specificity and other parameters that determine epidemic spread and which may be exploited to aid disease management (Li et al., 2009). For example, strains of Mycobacterium tuberculosis, the causative agent of human tuberculosis, have been shown to differ in pathogenicity and immunogenicity (López et al., 2003, Palanisamy et al., 2009, Valway et al., 1998), differences sometimes associated with variation in the $M$. tuberculosis genome (Manabe et al., 2003). 
We investigated whether genetically distinct strains of Mycobacterium bovis isolated during an eight year survey of the Northern Ireland cattle population varied in immunogenicity. Bovine TB is a serious endemic disease of both wildlife and livestock in many countries, transmissible to humans through consumption of unpasteurised milk or close contact with infected livestock. On-going efforts to eradicate bTB (e.g. EU directive 64/432/EEC) have resulted in several Western European countries being declared officially TB free. However, despite an intensive and expensive (Defra, 2011) programme of 'test and slaughter' of infected cattle over the past 50 years, bTB has recently undergone resurgence in parts of the UK (Abernethy et al., 2013, Goodchild and Clifton-Hadley, 2008). The failure to eradicate the disease in the British Isles may be at least partly due to the presence of a wildlife reservoir, the Eurasian badger (Meles meles) (Phillips et al., 2003).

In comparison with $M$. tuberculosis, relatively few studies have investigated genotype-phenotype associations in M. bovis. A survey of isolates from cattle in Great Britain indicated that skin test effectiveness and outbreak size were affected by pathogen genotype, leading to tentative suggestions that genotypes might vary in transmissibility and immunogenicity (Goodchild et al., 2003).

Variation among $M$. bovis strains in immunogenicity may lead to differential detectability using either the single intra-dermal tuberculin test (SIT) or the comparative tuberculin test (SICTT, henceforth skin test). The skin test is the primary means of detecting $M$. bovis in cattle in Northern Ireland and is based on a DTH response to injection of tuberculin (or Purified Protein Derivative, PPD) derived from the pathogen (PPD-B) and from M. avium (PPD-A). Animals that test positive (reactors) exhibit a $4 \mathrm{~mm}$ or larger increase in skin thickness at the PPD-B injection site compared with the PPD-A site. In both humans and animals (mice and guinea pigs) experimentally vaccinated with different strains of BCG (an attenuated form of $M$. bovis) DTH responses varied indicating that M. bovis strains vary in immunogenicity (reviewed by Ritz et al., 2008). . Similar variation among field strains might be exploited to aid the bTB eradication programme; the skin test might be applied 
using a lower cut off value or the interferon gamma blood test (de la Rua-Domenech et al., 2006) might be used in herds thought to harbour a less detectable strain.

Mycobacteria can be classified with increasing discrimination using large sequence and single nucleotide polymorphisms, direct repeat markers (spoligotyping) and then variable number of tandem repeat (VNTR) markers (Brudey et al., 2006, Gagneux and Small, 2007, Kato-Maeda et al., 2011, Ozcaglar et al., 2011, Supply et al., 2006). The majority of $M$. bovis isolates in Northern Ireland belong to a single spoligotype (SB0140) and so we used both spoligotyping and VNTR typing to define genotypes ("strains"). However, Goodchild et al. (2003) found evidence of phenotypic variation among different spoligotypes in Great Britain and also among VNTR types with the same spoligotype, so there is the tantalising possibility that exploitable variation might exist at these scales.

We assessed detectability of $M$. bovis genotypes to the skin test by estimating the ratio of skin-testdetected to undetected cases and by calculating the average size of the skin test response elicited at a disclosing test. Each year in Northern Ireland, one in four hundred animals slaughtered are found to have tuberculous lesions when inspected at standard (non-reactor) post mortem, despite having passed their most recent skin test. Undetected cases are also a feature of the bTB epidemics in both the Republic of Ireland and Great Britain (Clegg et al., 2011, Conlan et al., 2012, Karolemeas et al., 2012). One of our proxy measures of detectability was designed to indicate if pathogen genotype affected the outcome of the entire testing procedure, from measurement through interpretation of results to removal of animals (if necessary). The interpretation of individual skin tests may depend on the results of the entire herd test. For example, a skin test response that would normally be considered inconclusive may be reinterpreted as a positive result if other animals in the herd show positive responses (Enticott, 2012). Therefore, in theory genotypes with low immunogenicity might be detected more frequently using this measure if they occurred in mixed breakdowns with more immunogenic genotypes. To test for such effects we also compared the mean size of the skin test 
response elicited by each genotype at the disclosing test; if some genotypes elicited small responses close to the detection threshold they would be more likely to be missed by chance (or have results reinterpreted in the light of other results in the same herd test) than those that elicited much larger responses.

Using these two measures of detectability applied to M. bovis genotyping and cattle population data covering an eight year period, we addressed the following two questions: a) Does pathogen genotype influence the size of the skin response at the disclosing test? and b) Does the ratio of skin test detected to undetected cases vary among genotypes?

\section{Methods}

\subsection{Cattle population and TB control programme}

In Northern Ireland there were approximately 1.6 million cattle in around 25,000 herds in 2010 . The surveillance programme for bTB consists of at least annual skin testing of the entire cattle population and abattoir surveillance, along with laboratory confirmation and genotyping of confirmed cases (Abernethy et al., 2006, Abernethy et al., 2013, Skuce et al., 2010). An animal that exhibits an increase in skin thickness at the PPD-B site that is greater than $4 \mathrm{~mm}$ that at the PPD-A site (a PPD-B biased response) is declared a reactor (standard test interpretation). All animals destined for human consumption are inspected post-mortem for tuberculous lesions. Across Northern Ireland, approximately $12 \%$ of all suspected cases are detected post-mortem. Tissue samples taken from these animals and from reactors are subjected to histopathological tests and bacterial culture in order to confirm infection with M. bovis.

The genetic structure of the M. bovis population in Northern Ireland was surveyed between 2003 and 2010 (Skuce et al., 2010) using a set of markers selected systematically to provide high resolution of clonal relationships among herd breakdowns in the province (Skuce et al., 2005). Since 2003, the first M. bovis isolate from each newly confirmed herd breakdown was genotyped using a combination of spoligotyping and multi-locus VNTR analysis (MLVA) (Roring et al., 2002, Skuce et al., 
2005), provided that the herd had not had a confirmed TB case in the previous 365 days. Sampling was increased to two isolates from each breakdown in 2006 and to every confirmed isolate in 2009. The proportion of confirmed isolates genotyped increased from $65 \%$ in the first three years of the study to $92 \%$ in the remaining years, covering 10,931 herd breakdowns with at least one isolate genotyped (a total of 21,451 isolates). Of the breakdowns in which multiple isolates were sampled (i.e. 2006 onwards), $38 \%$ had more than one genotype present.

From this dataset, we excluded genotypes with less than ten isolates sampled in the period 2003 2010, retaining a total of 63 genotypes covering 10,498 herd breakdowns (Table S1). We combined this dataset with anonymised records of skin test results, details of animal life histories and movements which are stored within the Animal and Public Health Information System (APHIS) (Houston, 2001), a database administered by the Department of Agriculture and Rural Development.

\subsection{Response at the disclosing skin test}

We assessed the effect of pathogen genotype on skin test response (PPD-B - PPD-A) by comparing the influence of genotype with other potential sources of variation, extracting skin test results for animals that tested positive under the standard interpretation. We excluded animals that had an inconclusive result at the previous skin test because they might have become desensitised to tuberculin, characterised by a progressive decrease in response to each subsequent test by cattle undergoing repeated short interval testing (Coad et al., 2009) or those with advanced disease (de la Rua-Domenech et al., 2006). Following these exclusions, 11,799 animals remained, $78 \%$ of which were female. The distribution of skin test responses was right skewed, so values were log transformed prior to modelling (median $=12 \mathrm{~mm}$, lower quartile $=8 \mathrm{~mm}$, upper quartile $19 \mathrm{~mm}$ ).

We compared pathogen genotype with other potential sources of variation (age, sex, breed and test ID) by fitting a mixed effects linear regression model. Age (in months) and sex were included as fixed effects because males have slightly thicker skin than females (median baseline skin thickness at the bovine site: females $9 \mathrm{~mm}$, males $10 \mathrm{~mm}$, this dataset) and a shorter mean lifespan. Pathogen 
genotype and animal breed were included as random effects centred on the mean test response for each sex. Breeds vary in mean skin thickness which may affect the accuracy of skin measurements (Table 1) and may also vary in TB resistance and hence skin test response (Allen et al., 2010, Ameni et al., 2007, Bermingham et al., 2009). The final source of variation was the skin test ID which was unique to a given herd and date and was included to correct for variation among tests carried out for different reasons (e.g. annual herd tests or tracing of potential infected cattle), during different seasons and among testers. It also enabled us to combat non-independence of responses among animals. A large number of animals reacting at the same test may have been infected simultaneously, displaying similar sized responses which might bias estimates attributable to other factors.

We fitted the model using the Ime4 package (Bates et al., 2012) in $R 13.2$ (R Development Core Team, 2011); extracted batches of parameters associated with each source of variation and computed their (finite population) standard deviations. A factor whose groups vary widely in estimated coefficients is likely to have greater influence on the response variable than one whose group means are similar. Because the response had been log transformed, standard deviations for the different factors can be directly compared and when back transformed also indicate the predictive value (importance) of that factor on the original scale. To test for confounding of the comparative skin test response (PPD-B - PPD-A) with the PPD-A response we fitted a similar model using PPD-B response as the outcome variable. Estimates of both fixed and random effects were similar in both models (between-model correlations of estimated effects for genotypes and breeds, $r$ $=0.89$ and $r=0.95$ respectively) and so here we report only the comparative results.

\subsection{Ratio of skin test detected to undetected cases}

We investigated the effect of pathogen genotype on the ratio of detected to undetected cases using two approaches, firstly considering genotype as the sole explanatory factor and secondly attempting to adjust for potential variation in case detection rates among abattoirs. In our initial unadjusted 
analysis we compared the distribution of reactors with the distribution of cases undetected (i.e. only detected at abattoir) using a Chi-squared test. We carried out this comparison twice, first comparing the reactor distribution with that of all abattoir detected cases and then restricting our analysis to abattoir detected cases that had undergone a negative skin test within the 60 days prior to slaughter. Macroscopic lesions may appear in experimentally infected cattle within 3-6 weeks depending on the mode of infection, although the high infective doses used in these studies probably lead to faster disease progression than in naturally infected cattle (Neill et al., 2001). Therefore we could be reasonably confident that lesioned animals tested within the last 60 days had been infected prior to the last skin test and so can be considered "true undetected".

At the national level, the proportion of cases detected by the skin test is dependent on both the performance of the skin test and the rate of lesion detection at abattoir. Abattoirs in Republic of Ireland vary widely in lesion detection and subsequent bTB confirmation rates (Frankena et al., 2007, Olea-Popelka et al., 2012). We used the skin test detection ratio: the ratio of the incidence of cases detected by the skin test (number of reactors/number of animals skin tested in a given population during a given year) to the incidence of cases undetected as our measure of skin test effectiveness and then investigated the influence of pathogen genotype and abattoir. To calculate the incidence of cases undetected we selected animals that had a negative skin test and were slaughtered within 60 days, dividing the number of animals found to have lesions that were subsequently confirmed as bTB by the total number of animals within this group. We calculated the skin test detection ratios for the cattle populations associated with the twelve major abattoirs (anonymised) operating in Northern Ireland in each of the years 2003-2010. The catchment of each abattoir consisted of the herds from which it received non-reactor animals in a given year (the majority of reactors are handled by one or two specialised abattoirs).

We investigated whether skin test detection ratios varied as a result of the community composition of genotypes in the catchment area (e.g. a catchment might have a high ratio if dominated by a genotype that was relatively detectable). We calculated the relative abundance of genotypes in each 
catchment (animals slaughtered from herds where the focal genotype was detected / animals from herds where any genotype was detected). We then fitted a linear regression in $R$ modelling the skin test detection ratio, $D$ as a function of the relative genotype abundances in that catchment and year:

$$
D \sim \beta_{0} s_{0}+\beta_{1} s_{1}+\beta_{2} s_{2}+\ldots+\beta_{n} s_{n}
$$

where $s_{0 . . .} s_{n}$ are the relative genotype abundances and $\beta_{0 . . .} \beta_{n}$ are coefficients to be estimated indicating genotype effects. We hypothesised that if pathogen genotypes varied in detectability then the estimated genotype effects on skin test detection ratio would vary, with some deviating significantly from zero. Alternatively, if differences in abattoir procedures rather than genotype effects were influencing detection ratios then the estimated parameters would be close to zero.

\section{Results}

\subsection{Response at the disclosing skin test}

Skin test responses varied considerably at the disclosing test (range $5-94 \mathrm{~mm}, 95 \%$ quantile $39 \mathrm{~mm}$ ) but we found little variation among genotypes in the mean response elicited. Response size decreased by $0.3 \mathrm{~mm}$ for each additional year of age and females had a significantly smaller response than males; estimated mean skin rises at 24 months age (females $=13.2 \mathrm{~mm}, 95 \%$ Cls: $12.7 \mathrm{~mm}$, $13.8 \mathrm{~mm} ;$ males $=14.8 \mathrm{~mm}[14.4 \mathrm{~mm}, 15.3 \mathrm{~mm}])$. Estimated genotype effects were clustered tightly around these values, all within $1.5 \mathrm{~mm}$ of the respective mean (Figure 1 ) with a correspondingly low standard deviation (Table 2). Cls for the majority of genotypes overlapped zero indicating no significant differences from the overall mean with the exception of genotype 5.140 which had $1.2 \mathrm{~mm}$ larger skin test responses than average. However the maximum difference between the response for this genotype in comparison with another was only $2.2 \mathrm{~mm}$ (c.f. genotype 10.140). We observed no systematic differences in skin test response among spoligotypes (genotypes with different spoligotypes interspersed throughout the range of responses, Figure 1). 
There was a similar degree of variation among cattle breeds as among genotypes (Table 2) with one breeds (Charolais) having significantly greater skin test responses than average and one breed (Simmental) having significantly smaller responses (Figure 2). Estimated skin test responses were not correlated with breed skin thickness (mean skin fold thickness at PPD-B site at initial skin test measurement; Pearson $r=-0.10$, d.f. $=45, P=0.51$; Table 1 ) indicating that variation in breed responses was not the result of measurement error due to variation in skin thickness. Variation among skin tests (test IDs) was approximately three times greater than that among $M$. bovis genotypes and cattle breeds. Residual standard deviation (between animals within groups) was an order of magnitude greater than that between groups associated with any of the factors (Table 2), translating to considerable variation on the data scale (average predicted response $=13.2 \mathrm{~mm}, \pm$ 1SD: $7.6-23.1 \mathrm{~mm}$ ). High residual variation at the individual level indicates that the selected factors are poor predictors of skin test response and that inter-animal variation has a far greater influence; potentially a result of genetic variation in resistance to bTB (Allen et al., 2010, Bermingham et al., 2009). This result may also reflect the difficulties of accurately measuring skin thicknesses under field conditions; measurement to the nearest millimetre is the best that can reasonably be expected. Therefore the increased skin test response elicited in animals infected with genotype 5.140, whilst being an outlier, is unlikely to have significant implications for disease management.

\subsection{Ratio of skin test detected to undetected cases}

The proportion of cases detected by the skin test varied among genotypes in univariate analysis but we found no significant influence of genotypes on skin test detection ratios once abattoir effects had been accounted for, indicating that differences in the proportion of cases detected was most probably not caused by genotype effects. Our initial analysis unadjusted for abattoir effects showed that the distribution of genotypes among reactors was significantly different from the distribution of abattoir detected cases both when considering all abattoir cases $\left(X^{2}=418\right.$, d.f. $=62, P<0.001$, Table S1) and only those animals slaughtered within 60 days of a negative skin test $\left(X^{2}=276\right.$, d.f. $=62, P<$ 
0.001). Thirty one percent of abattoir detected cases were from animals slaughtered within the 60 day period.

To adjust for abattoir effects we calculated skin test detection ratios for a total of 83 different catchment $\times$ year combinations across the twelve abattoirs. In general, skin test detection rates were not associated with abattoir detection rates; there was no significant correlation between the incidence of detected and undetected cases across all catchment years (Pearson $r=0.10, P=0.38$ ). There was considerable variation among catchments in the skin test detection ratio, ranging from catchments with an almost equal ratio of case types (e.g. Figure3a., abattoir A) to those with only one case found at abattoir for every seven reactors (e.g. abattoir $\mathrm{K}$ ) and there was also considerable inter-annual variation in incidence of TB and skin test detection ratios (Figure 3). Catchments were large (median distance travelled to abattoir $=54 \mathrm{~km}$, quartiles $=23 \mathrm{~km}, 89 \mathrm{~km}$ ) and contained many genotypes (median $=29$, range $14-46$ genotypes). The relative abundance of genotypes in each catchment was low with only three genotypes representing more than $10 \%$ of the confirmed bTB in any given catchment (Supplementary information, Table S1).

Skin test detection ratios varied among abattoir catchments but these differences were unrelated to the community composition of pathogen genotypes. None of the estimated genotype effects exerted an influence on the skin test detection ratio that was significantly different from zero (Table S1, all 95\% Cls overlap zero), so genotype detectability does not appear to significantly influence the effectiveness of the skin testing programme. There were no systematic differences among spoligotypes (magnitude of genotype effects were not clustered by spoligotype Table S1). Half of the variance in skin test detection ratios was explained by the fitted model $\left(R^{2}=0.51\right)$, indicating a reasonably good fit to the data. We conclude that the observed variation among genotypes in the proportion of cases detected by the skin test (unadjusted models) was largely driven by variation among abattoirs in TB lesion detection rates. Taken in parallel with our finding that skin test 
responses do not vary with pathogen genotype, there is no convincing evidence that genotypes of M. bovis in Northern Ireland vary significantly in detectability using the skin test.

\section{Discussion}

The observed variation in the skin test detection ratios among abattoir catchments and years can be interpreted either in terms of abattoir or skin test performance. Many factors potentially alter skin test sensitivity in the field including those affecting the immune response of the animal (e.g. genetic variation in resistance, time since infection, stress or co-infection with other pathogens including liver fluke or Johne's disease), the tuberculin used (variation in batch potency) and test methodology (e.g. errors in measurement or recording) (Allen et al., 2010, Enticott, 2012, Good et al., 2011, de la Rua-Domenech et al., 2006). These factors contribute towards the moderate individual level test sensitivity of the skin test; two recent meta-analyses estimating sensitivity to be significantly less than one: sensitivity $0.51[95 \% \mathrm{Cl}, 0.29,0.73]$ (Downs et al., 2011) and $0.80[0.72,0.86]$ (Hartnack and Torgerson, 2012). Under field conditions the skin test has been found to be less sensitive than both existing (interferon gamma) and new (Enferplex-TB) alternative diagnostic tests (Clegg et al., 2011). Despite these difficulties the herd level sensitivity of the skin test increases rapidly as the number of infected animals increases (Christensen and Gardner, 2000). Once infection has been detected in a herd the regime of repeat short-interval testing, usually coupled with a more severe interpretation of the test is likely to disclose animals that were missed initially. Therefore at the scale of an entire abattoir catchment, reactor incidence is likely to give a good representation of bTB incidence in a given year.

Surveys of abattoirs in the Republic of Ireland have demonstrated that abattoirs vary in the number of lesions submitted that are subsequently confirmed, and that these rates were largely independent of the risk profiles of the animals sent to them (i.e. the variation was in abattoir surveillance rather than in incidence of bTB in the cattle population) (Frankena et al., 2007, OleaPopelka et al., 2012). Our results were similar, with the incidence of cases detected at abattoir 
(representing a combination of lesion submission and confirmation risk) varying widely among abattoirs and among years. We suggest that the effectiveness of abattoir surveillance is related to the business model in place, possibly including the line speed at each plant. Skin test detection ratios were lowest for plants A and B, indicating that a large number of lesions were being detected. These abattoirs specialise in processing animals surviving beyond the 30 month point at which most beef cattle are slaughtered. There are relatively few old cattle to process each year and these abattoirs may also maintain a slower than average line speed (C. McCormick pers. comm.). As a consequence there may be more time for each carcass to be inspected and therefore more lesions may be detected.

We found no convincing evidence for variation among genotypes in detectability to the skin test, either at the spoligotype or tandem repeat level of discrimination, for which there are a number of potential explanations. Firstly, it is possible that the genotypes that we identified are too closely related to exhibit any significant variation in detectability. All of the genotypes found in our dataset and the majority of those found in the UK are part of the EU1 clonal complex of $M$. bovis (Smith et al., 2011), dominated in Northern Ireland by spoligotypes SB0140 and SB0142 (Smith et al., 2006). In Northern Ireland, diversity of strains, as measured by spoligotype is even more tightly restricted in comparison with the rest of the UK (Smith et al., 2006, Skuce et al., 2010). The markers that we used to distinguish genotypes, both spoligo spacers and tandem repeats, were selected to provide maximum discrimination among isolates in the study population (Skuce et al., 2005) representative of Northern Ireland. These genetic markers are not currently thought to be adaptive but are assumed to be representative of clonal relationships, with some clones potentially having acquired functional changes. Even if our genetic markers are associated with adaptive mutations (perhaps through genetic hitch-hiking: Barton, 2000, Smith et al., 2006), the genotypes identified in this study may have had insufficient time to evolve any significant variations in detectability in the 50 years since compulsory slaughter of infected animals was introduced (Smith et al., 2006). This is a short period in comparison with the millennia taken for significant changes to accrue among the major 
lineages in the M. tuberculosis complex (Comas and Gagneux, 2009). However, recent evidence suggests that in the recent phylogeography of $M$. bovis, neutral rather than adaptive effects are responsible for the major global patterns of genetic diversity (Smith et al., 2011) and given the relatively recent population bottlenecks it is perhaps unsurprising that we did not find significant variation in detectability.

Our findings do not preclude the existence of phenotypic variation among genotypes at broader phylogenetic scales as exhibited among M. tuberculosis lineages (Gagneux and Small, 2007, Krishnan et al., 2011, Gagneux et al., 2006, Brown et al., 2010) and so an interesting avenue of research would be to compare $M$. bovis genotypes across countries with different lineage compositions. A comparison could be made between the EU1 genotypes identified in this study and samples taken from continental Europe where non-EU1 genotypes are more prevalent, although identifying and combining representative datasets at the international level presents a significant logistical challenge.

Alternatively, there might be a trade-off between immunogenicity and traits that allow $M$. bovis to establish in susceptible cattle. M. tuberculosis genes coding for certain epitopes (host recognised molecules) are among the most highly conserved in the pathogen genome (Comas and Gagneux, 2011), indicating that host recognition is fundamental to pathogen transmission and survival. In contrast to pathogens which attempt to evade the host immune system it appears that some Mycobacteria require a host response as an integral part of the infection process of which granuloma formation is a key feature (Davis and Ramakrishnan, 2009, Paige and Bishai, 2010). A similar mechanism might be in action here in that $M$. bovis genotypes could be disadvantaged if their immunogenicity was altered to evade the skin test because in doing so they might compromise their ability to establish in new hosts following transmission. However, the relationship between immunogenicity and infection traits is not well defined and requires further investigation to establish whether such a trade-off exists. For example, similar skin test responses were observed in cattle experimentally infected with different strains of $M$. bovis, only one of which elicited extensive 
macroscopic lesions (Wedlock et al., 1999). Similarly, experimental infection of cattle with different species of mycobacteria (M. bovis, $M$. tuberculosis and $M$. kansasii) elicited strong immune responses in each case but the degree of subsequent tissue colonisation and pathology induced varied among species (Waters et al., 2010).

Routine genotyping of $M$. bovis isolates is indubitably valuable for epidemiological tracing. The genotypes present in Northern Ireland do not differ in detectability and so genotype-specific alterations to the testing regime (e.g. use of the interferon gamma test or a more severe interpretation of the skin test if a less detectable strain is known to be present in a herd) do not appear to be warranted. However, the lack of variation amongst $M$. bovis genotypes in detectability using the skin test in the $\mathrm{NI}$ population does not exclude the possibility of significant variation in other traits, and an obvious future line of investigation using this dataset would be to compare sizes of herd breakdown for different genotypes as a proxy measure of transmissibility.

\subsection{Conclusions}

We investigated the hypothesis that genotypically distinct strains of $M$. bovis might vary in detectability using the tuberculin skin test. Linking a province wide survey of field isolated genotypes in Northern Ireland with records of skin tests and animal movements we calculated two measures of detectability using the skin test. We found no substantial variation among genotypes in the size of response elicited at the disclosing test. Skin test detection ratios in abattoir catchments were not related to the composition of the genotype community, instead varying considerably between abattoirs and years, possibly as a result of different abattoir performance. Considering both of these measures, we conclude that $M$. bovis genotypes in Northern Ireland do not differ significantly in detectability to the skin test, either because they are too closely related or perhaps as a result of an evolutionary trade off with genotype virulence which we seek to investigate further.

\section{Acknowledgments}


This study was funded by the BBSRC under the CEDFAS initiative; grant numbers BB/E018335/1 and

BB/E018335/2. SCB, JAW and EJG also acknowledge BBSRC Institute Strategic Programme funding.

We thank the administrators of APHIS for access to animal level data. Comments from Maria

O'Hagan and two anonymous reviewers greatly improved the paper.

\section{References}

Abernethy, D.A., Denny, G.O., Menzies, F.D., McGuckian, P., Honhold, N., Roberts, A.R., 2006. The Northern Ireland programme for the control and eradication of Mycobacterium bovis. Vet. Microbiol $112,231-237$.

Abernethy, D.A., Upton, P., Higgins, I.M., McGrath, G., Goodchild, A.V., Rolfe, S.J., Broughan, J.M., Downs, S.H., Clifton-Hadley, R., Menzies, F.D., de la Rua-Domenech, R., Blissitt, M.J., Duignan, A., More, S.J., 2013. Bovine tuberculosis trends in the UK and the Republic of Ireland, 1995-2010. Veterinary Record.

Allen, A.R., Minozzi, G., Glass, E.J., Skuce, R.A., McDowell, S.W.J., Woolliams, J.A., Bishop, S.C., 2010. Bovine tuberculosis: the genetic basis of host susceptibility. Proceedings of the Royal Society B: Biological Sciences 277, 2737-2745.

Ameni, G., Aseffa, A., Engers, H., Young, D., Gordon, S., Hewinson, G., Vordermeier, M., 2007. High prevalence and increased severity of pathology of bovine tuberculosis in Holsteins compared to Zebu breeds under field cattle husbandry in Central Ethiopia. Clinical and Vaccine Immunology 14, 13561361.

Barton, N.H., 2000. Genetic hitchhiking. Philos Trans R Soc Lond B Biol Sci 355, 1553-1562.

Bates, D., Maechler, M., Bolker, B., 2012. Ime4: Linear mixed-effects models using S4 classes.

Bermingham, M.L., More, S.J., Good, M., Cromie, A.R., Higgins, I.M., Brotherstone, S., Berry, D.P., 2009. Genetics of tuberculosis in Irish Holstein-Friesian dairy herds. J. Dairy Sci. 92, 3447-3456.

Brown, T., Nikolayevskyy, V., Velji, P., Drobniewski, F., 2010. Associations between Mycobacterium tuberculosis strains and phenotypes. Emerg Infect Dis 16, 272-280.

Brudey, K., Driscoll, J.R., Rigouts, L., Prodinger, W.M., Gori, A., Al-Hajoj, S.A., Allix, C., Aristimuño, L., Arora, J., Baumanis, V., Binder, L., Cafrune, P., Cataldi, A., Cheong, S., Diel, R., Ellermeier, C., Evans, J.T., Fauville-Dufaux, M., Ferdinand, S., Garcia de Viedma, D., Garzelli, C., Gazzola, L., Gomes, H.M., Guttierez, M.C., Hawkey, P.M., van Helden, P.D., Kadival, G.V., Kreiswirth, B.N., Kremer, K., Kubin, M., Kulkarni, S.P., Liens, B., Lillebaek, T., Ho, M.L., Martin, C., Martin, C., Mokrousov, I., Narvskaïa, O., Ngeow, Y.F., Naumann, L., Niemann, S., Parwati, I., Rahim, Z., Rasolofo-Razanamparany, V., Rasolonavalona, T., Rossetti, M.L., Rüsch-Gerdes, S., Sajduda, A., Samper, S., Shemyakin, I.G., Singh, U.B., Somoskovi, A., Skuce, R.A., van Soolingen, D., Streicher, E.M., Suffys, P.N., Tortoli, E., Tracevska, T., Vincent, V., Victor, T.C., Warren, R.M., Yap, S.F., Zaman, K., Portaels, F., Rastogi, N., Sola, C., 2006. Mycobacterium tuberculosis complex genetic diversity: mining the fourth international spoligotyping database (SpolDB4) for classification, population genetics and epidemiology. BMC Microbiol. 6. 
Christensen, J., Gardner, I.A., 2000. Herd-level interpretation of test results for epidemiologic studies of animal diseases. Preventive Veterinary Medicine 45, 83-106.

Clegg, T.A., Duignan, A., Whelan, C., Gormley, E., Good, M., Clarke, J., Toft, N., More, S.J., 2011. Using latent class analysis to estimate the test characteristics of the $\gamma$-interferon test, the single intradermal comparative tuberculin test and a multiplex immunoassay under Irish conditions. Veterinary Microbiology 151, 68-76.

Coad, M., Clifford, D., Rhodes, S.G., Hewinson, R.G., Vordermeier, H.M., Whelan, A.O., 2009. Repeat tuberculin skin testing leads to desensitisation in naturally infected tuberculous cattle which is associated with elevated interleukin-10 and decreased interleukin-1 beta responses. Vet. Res. 41.

Comas, I., Gagneux, S., 2011. A role for systems epidemiology in tuberculosis research. Trends in Microbiology 19, 492-500.

Comas, I., Gagneux, S., 2009. The past and future of tuberculosis research. PLoS Pathog 5.

Conlan, A.J.K., McKinley, T.J., Karolemeas, K., Pollock, E.B., Goodchild, A.V., Mitchell, A.P., Birch, C.P.D., Clifton-Hadley, R.S., Wood, J.L.N., 2012. Estimating the hidden burden of bovine tuberculosis in Great Britain. PLoS Computational Biology 8.

Davis, J.M., Ramakrishnan, L., 2009. The role of the granuloma in expansion and dissemination of early tuberculous infection. Cell 136, 37-49.

de la Rua-Domenech, R., Goodchild, A.T., Vordermeier, H.M., Hewinson, R.G., Christiansen, K.H., Clifton-Hadley, R.S., 2006. Ante mortem diagnosis of tuberculosis in cattle: A review of the tuberculin tests, $\gamma$-interferon assay and other ancillary diagnostic techniques. Research in Veterinary Science 81, 190-210.

Defra, 2011. Bovine TB eradication programme for England.

Downs, S.H., Parry, J., Nunez-Garcia, J., Abernethy, D.A., Broughan, J.M., Cameron, A.R., Cook, A.J., de la Rua Domensch, R., Goodchild, A.V., Greiner, M., Gunn, J., More, S.J., Rhodes, S., Rolfe, S., Sharp, M., Upton, H.M., Vordermeier, H.M., Watson, E., Welsh, M., Whelan, A.O., 2011. Metaanalysis of diagnostic test performance and modelling of testing strategies for control of bovine tuberculosis. Proceedings of the Society for Veterinary Epidemiology and Preventive Medicine , 139153.

Enticott, G., 2012. The local universality of veterinary expertise and the geography of animal disease. Transactions of the Institute of British Geographers 37, 75-88.

Frankena, K., White, P.W., O'Keeffe, J., Costello, E., Martin, S.W., van Grevenhof, I., More, S.J., 2007. Quantification of the relative efficiency of factory surveillance in the disclosure of tuberculosis lesions in attested Irish cattle. Veterinary Record 161, 679-684.

Gagneux, S., DeRiemer, K., Van, T., Kato-Maeda, M., de Jong, B.C., Narayanan, S., Nicol, M., Niemann, S., Kremer, K., Gutierrez, M.C., Hilty, M., Hopewell, P.C., Small, P.M., 2006. Variable hostpathogen compatibility in Mycobacterium tuberculosis. Proceedings of the National Academy of Sciences of the United States of America 103, 2869-2873. 
Gagneux, S., Small, P.M., 2007. Global phylogeography of Mycobacterium tuberculosis and implications for tuberculosis product development. The Lancet Infectious Diseases 7, 328-337.

Good, M., Clegg, T.A., Costello, E., More, S.J., 2011. The comparative performance of the single intradermal test and the single intradermal comparative tuberculin test in Irish cattle, using tuberculin PPD combinations of differing potencies. The Veterinary Journal 190, e60-e65.

Goodchild, A.V., de la Rua-Domenech, R., Palmer, S., Dale, J., Gordon, S.V., Hewinson, G.R., CliftonHadley, R.S., 2003. Association between molecular type and the epidemiological features of Mycobacterium bovis in cattle. Proceedings of the Annual Conference of the Society for Veterinary Epidemiology and Public Health , 45-59.

Goodchild, T., Clifton-Hadley, R., 2008. The fall and rise of bovine tuberculosis in Great Britain, in Thoen, C.O., Steele, J.H., Gilsdorf, M.J. (Eds.), Mycobacterium Bovis Infection in Animals and Humans. Blackwell Publishing Ltd, pp. 100-116.

Hartnack, S., Torgerson, P.R., 2012. The accuracy of the single intradermal comparative skin test for the diagnosis of bovine tuberculosis-estimated from a systematic literature search. Mycobacterial Diseases 2(6), 1000120.

Houston, R., 2001. A computerised database system for bovine traceability. Rev. - Off. Int. Epizoot 20, 652-661.

Karolemeas, K., de la Rua-Domenech, R., Cooper, R., Goodchild, A.V., Clifton-Hadley, R.S., Conlan, A.J.K., Mitchell, A.P., Hewinson, R.G., Donnelly, C.A., Wood, J.L.N., McKinley, T.J., 2012. Estimation of the relative sensitivity of the comparative tuberculin skin test in tuberculous cattle herds subjected to depopulation. PLOS ONE 7.

Kato-Maeda, M., Gagneux, S., Flores, L.L., Kim, E.Y., Small, P.M., Desmond, E.P., Hopewell, P.C., 2011. Strain classification of Mycobacterium tuberculosis: congruence between large sequence polymorphisms and spoligotypes. Int. J. Tuberc. Lung Dis. 15, 131-133.

Krishnan, N., Malaga, W., Constant, P., Caws, M., Thi Hoang Chau, T., Salmons, J., Thi Ngoc Lan, N., Bang, N.D., Daffé, M., Young, D.B., Robertson, B.D., Guilhot, C., Thwaites, G.E., 2011. Mycobacterium tuberculosis lineage influences innate immune response and virulence and is associated with distinct cell envelope lipid profiles. PLoS ONE 6, e23870.

Li, W., Raoult, D., Fournier, P., 2009. Bacterial strain typing in the genomic era. FEMS Microbiology Reviews 33, 892-916.

López, B., Aguilar, D., Orozco, H., Burger, M., Espitia, C., Ritacco, V., Barrera, L., Kremer, K., Hernandez-pando, R., Huygen, K., Van Soolingen, D., 2003. A marked difference in pathogenesis and immune response induced by different Mycobacterium tuberculosis genotypes. Clinical \& Experimental Immunology 133, 30-37.

Manabe, Y.C., Dannenberg, A.M., Tyagi, S.K., Hatem, C.L., Yoder, M., Woolwine, S.C., Zook, B.C., Pitt, M.L.M., Bishai, W.R., 2003. Different strains of Mycobacterium tuberculosis cause various spectrums of disease in the rabbit model of tuberculosis. Infection and Immunity 71, 6004-6011.

Neill, S.D., Bryson, D.G., Pollock, J.M., 2001. Pathogenesis of tuberculosis in cattle. Tuberculosis 81, 79-86. 
Olea-Popelka, F., Freeman, Z., White, P., Costello, E., O'Keeffe, J., Frankena, K., Martin, W., More, S., Lima, M.S., Pascoal, R.A., others, 2012. Relative effectiveness of Irish factories in the surveillance of slaughtered cattle for visible lesions of tuberculosis, 2005-2007. Irish Veterinary Journal 65, 2.

Ozcaglar, C., Shabbeer, A., Vandenberg, S., Yener, B., Bennett, K.P., 2011. Sublineage structure analysis of Mycobacterium tuberculosis complex strains using multiple-biomarker tensors. BMC genomics 12.

Paige, C., Bishai, W.R., 2010. Penitentiary or penthouse condo: the tuberculous granuloma from the microbe's point of view. Cellular Microbiology 12, 301-309.

Palanisamy, G.S., DuTeau, N., Eisenach, K.D., Cave, D.M., Theus, S.A., Kreiswirth, B.N., Basaraba, R.J., Orme, I.M., 2009. Clinical strains of Mycobacterium tuberculosis display a wide range of virulence in guinea pigs. Tuberculosis 89, 203-209.

Phillips, C.J.C., Foster, C.R.W., Morris, P.A., Teverson, R., 2003. The transmission of Mycobacterium bovis infection to cattle. Research in Veterinary Science 74, 1-15.

R Development Core Team, 2011. R: A Language and Environment for Statistical Computing. $R$ Foundation for Statistical Computing, Vienna, Austria.

Ritz, N., Hanekom, W.A., Robins-Browne, R., Britton, W.J., Curtis, N., 2008. Influence of BCG vaccine strain on the immune response and protection against tuberculosis. FEMS Microbiology Reviews 32, 821-841.

Roring, S., Scott, A., Brittain, D., Walker, I., Hewinson, G., Neill, S., Skuce, R., 2002. Development of variable-number tandem repeat typing of Mycobacterium bovis: comparison of results with those obtained by using existing exact tandem repeats and spoligotyping. J Clin Microbiol 40, 2126-2133.

Skuce, R.A., Mallon, T.R., McCormick, C.M., McBride, S.H., Clarke, G., Thompson, A., Couzens, C., Gordon, A.W., McDowell, S.W.J., 2010. Mycobacterium bovis genotypes in Northern Ireland: herdlevel surveillance (2003 to 2008). Veterinary Record 167, 684-689.

Skuce, R.A., McDowell, S.W., Mallon, T.R., Luke, B., Breadon, E.L., Lagan, P.L., McCormick, C.M., McBride, S.H., Pollock, J.M., 2005. Discrimination of isolates of Mycobacterium bovis in Northern Ireland on the basis of variable numbers of tandem repeats (VNTRs). The Veterinary Record 157, 501-504.

Smith, N.H., Berg, S., Dale, J., Allen, A., Rodriguez, S., Romero, B., Matos, F., Ghebremichael, S., Karoui, C., Donati, C., Machado, A.d.C., Mucavele, C., Kazwala, R.R., Hilty, M., Cadmus, S., Ngandolo, B.N.R., Habtamu, M., Oloya, J., Muller, A., Milian-Suazo, F., Andrievskaia, O., Projahn, M., Barandiarán, S., Macías, A., Müller, B., Zanini, M.S., Ikuta, C.Y., Rodriguez, C.A.R., Pinheiro, S.R., Figueroa, A., Cho, S., Mosavari, N., Chuang, P., Jou, R., Zinsstag, J., van Soolingen, D., Costello, E., Aseffa, A., Proaño-Perez, F., Portaels, F., Rigouts, L., Cataldi, A.A., Collins, D.M., Boschiroli, M.L., Hewinson, R.G., Neto, J.S.F., Surujballi, O., Tadyon, K., Botelho, A., Zárraga, A.M., Buller, N., Skuce, R., Michel, A., Aranaz, A., Gordon, S.V., Jeon, B., Källenius, G., Niemann, S., Boniotti, M.B., van Helden, P.D., Harris, B., Zumárraga, M.J., Kremer, K., 2011. European 1: A globally important clonal complex of Mycobacterium bovis. Infection, Genetics and Evolution 11, 1340-1351. 
Smith, N.H., Gordon, S.V., de la Rua-Domenech, R., Clifton-Hadley, R.S., Hewinson, R.G., 2006. Bottlenecks and broomsticks: the molecular evolution of Mycobacterium bovis. Nat Rev Micro 4, 670-681.

Supply, P., Allix, C., Lesjean, S., Cardoso-Oelemann, M., Rüsch-Gerdes, S., Willery, E., Savine, E., de Haas, P., van Deutekom, H., Roring, S., Bifani, P., Kurepina, N., Kreiswirth, B., Sola, C., Rastogi, N., Vatin, V., Gutierrez, M.C., Fauville, M., Niemann, S., Skuce, R., Kremer, K., Locht, C., van Soolingen, D., 2006. Proposal for standardization of optimized mycobacterial interspersed repetitive unitvariable-number tandem repeat typing of Mycobacterium tuberculosis. J. Clin. Microbiol. 44, 44984510.

Valway, S.E., Sanchez, M.P.C., Shinnick, T.F., Orme, I., Agerton, T., Hoy, D., Jones, J.S., Westmoreland, H., Onorato, I.M., 1998. An outbreak involving extensive transmission of a virulent strain of Mycobacterium tuberculosis. New England Journal of Medicine 338, 633-639.

Waters, W.R., Whelan, A.O., Lyashchenko, K.P., Greenwald, R., Palmer, M.V., Harris, B.N., Hewinson, R.G., Vordermeier, H.M., 2010. Immune responses in cattle inoculated with Mycobacterium bovis, Mycobacterium tuberculosis, or Mycobacterium kansasii. Clinical and Vaccine Immunology 17, 247-252.

Wedlock, D.N., Aldwell, F.E., Collins, D.M., de Lisle, G.W., Wilson, T., Buddle, B.M., 1999. Immune responses induced in cattle by virulent and attenuated Mycobacterium bovis strains: correlation of delayed-type hypersensitivity with ability of strains to grow in macrophages. Infection and Immunity 67, 2172-2177. 


\section{Tables}

Table 1. Mean skin fold thickness at PPD-B site at initial skin test measurement of seventeen cattle breeds.

\begin{tabular}{|c|c|c|c|}
\hline Breed & Code & $\begin{array}{l}\text { Initial skin } \\
\text { thickness (mm) }\end{array}$ & Std. Dev. \\
\hline Aberdeen Angus & $A A$ & 9.1 & 0.1 \\
\hline Ayrshire & AYR & 7.5 & 0.2 \\
\hline Belgian Blue & BB & 8.9 & 0.1 \\
\hline Charolais & $\mathrm{CH}$ & 9.8 & 0 \\
\hline Blonde D'Aquitaine & DAQ & 9.6 & 0.1 \\
\hline Friesian & FR & 7.7 & 0 \\
\hline Hereford & HER & 9.4 & 0.1 \\
\hline Holstein & $\mathrm{HOL}$ & 7.9 & 0.1 \\
\hline Jersey & JER & 7.3 & 0.2 \\
\hline Limousin & LIM & 9.4 & 0 \\
\hline Montbeliarde & MB & 9 & 0.2 \\
\hline Meuse Rhine Issel & MRI & 7.7 & 0.5 \\
\hline Salers & SAL & 9.9 & 0.2 \\
\hline Swiss Brown & SBR & 8.7 & 0.6 \\
\hline South Devon & SD & 8.6 & 0.6 \\
\hline Shorthorn & $\mathrm{SH}$ & 8.3 & 0.2 \\
\hline Simmental & SIM & 9.7 & 0.1 \\
\hline
\end{tabular}


Table 2. Influence of multiple factors on skin test response at the disclosing test. Standard deviation of estimated coefficients for each factor displayed. Abbreviations: Test ID: test identity number, Std. Dev.: standard deviation.

\begin{tabular}{lll}
\hline Factor & Groups & Std. Dev. \\
\hline Test ID & 4927 & 0.065 \\
Genotype & 62 & 0.026 \\
Breed & 47 & 0.017 \\
Residual & 12012 & 0.558
\end{tabular}




\section{Supplementary Information}

Table S1. Influence of $M$. bovis genotype on modelled skin test detection ratio across catchments of twelve abattoirs in Northern Ireland during an eight year period, along with proportion of cases undetected by the skin test (detected at abattoir). Number of catchment years (abattoir $\times$ year) shown along with mean relative abundance of each genotype in catchment years where detected. Genotypes names [VNTR type.Spoligotype], VNTR pattern (loci ordered left-right: mv2163b, mv4052, mv2461, mv1955, mv1895, mv2165, mv2163a, mv3232) and spoligotype octal codes given.

\begin{tabular}{|c|c|c|c|c|c|c|c|c|}
\hline Genotype & VNTR pattern & Spoligotype octal code & Effect & $\begin{array}{l}\text { Lower } \\
95 \% \mathrm{Cl}\end{array}$ & $\begin{array}{l}\text { Upper } \\
95 \% \mathrm{Cl}\end{array}$ & $\begin{array}{l}\text { Catchment } \\
\text { years }\end{array}$ & $\begin{array}{c}\text { Relative } \\
\text { abundance } \\
(\%)\end{array}$ & $\begin{array}{c}\text { Proportion } \\
\text { of cases } \\
\text { undetected } \\
\text { by skin test }\end{array}$ \\
\hline 2.142 & $4-4-5-3-3-7-11-7$ & 664073777763600 & 0.001 & -0.157 & 0.159 & 83 & 20.4 & 0.25 \\
\hline 1.140 & $4-4-5-3-4-7-11-9$ & 664073777777600 & 0.177 & -0.01 & 0.365 & 83 & 16 & 0.24 \\
\hline 5.140 & $4-2-5-3-4-7-11-7$ & 664073777777600 & 0.148 & -0.123 & 0.419 & 83 & 10.9 & 0.23 \\
\hline 4.140 & $4-4-5-3-4-7-11-7$ & 664073777777600 & 0.037 & -0.348 & 0.421 & 82 & 7 & 0.29 \\
\hline 6.263 & $4-4-4-1-4-7-10-7$ & 664073774037600 & 0.058 & -0.283 & 0.399 & 81 & 7 & 0.31 \\
\hline 7.140 & $4-4-5-1-4-6-10-9$ & 664073777777600 & 0.074 & -0.336 & 0.485 & 82 & 6.1 & 0.24 \\
\hline 3.140 & $4-4-5-1-4-6-10-7$ & 664073777777600 & 0.324 & -0.094 & 0.743 & 82 & 5.2 & 0.35 \\
\hline 11.145 & $3-3-3-3-4-7-11-8$ & 640013777777600 & 0.096 & -0.194 & 0.386 & 74 & 3.9 & 0.14 \\
\hline 9.273 & $4-4-4-3-2-7-6-8$ & 664073777777200 & -0.259 & -0.725 & 0.207 & 69 & 2.9 & 0.20 \\
\hline 117.140 & $4-4-5-3-4-6-10-9$ & 664073777777600 & -0.125 & -0.533 & 0.284 & 47 & 2.3 & 0.33 \\
\hline 24.130 & $3-3-4-2-2-7-11-7$ & 676573777777600 & -0.54 & -1.217 & 0.138 & 64 & 2.1 & 0.53 \\
\hline 14.140 & $3-4-5-3-4-7-11-7$ & 664073777777600 & -0.064 & -0.839 & 0.711 & 66 & 2.1 & 0.49 \\
\hline 146.140 & $4-4-5-1-4-5-10-9$ & 664073777777600 & -1.54 & -4.491 & 1.411 & 8 & 1.9 & 0.43 \\
\hline 15.140 & $4-2-4-3-4-7-11-7$ & 664073777777600 & -0.426 & -1.08 & 0.227 & 64 & 1.9 & 0.25 \\
\hline 19.140 & $4-4-5-3-4-7-11-4$ & 664073777777600 & 0.223 & -0.396 & 0.842 & 78 & 1.9 & 0.29 \\
\hline 112.140 & $4-4-5-1-4-5-10-7$ & 664073777777600 & -0.054 & -0.562 & 0.454 & 19 & 1.6 & 0.25 \\
\hline 25.140 & $3-4-5-1-4-6-10-7$ & 664073777777600 & -0.043 & -0.788 & 0.702 & 65 & 1.6 & 0.57 \\
\hline 8.140 & $4-2-5-3-4-6-11-7$ & 664073777777600 & 0.557 & -0.286 & 1.399 & 74 & 1.5 & 0.33 \\
\hline 13.140 & $4-4-5-3-4-6-11-9$ & 664073777777600 & -0.929 & -2.004 & 0.147 & 69 & 1.3 & 0.28 \\
\hline 42.142 & $3-4-5-3-3-7-11-7$ & 664073777763600 & -0.03 & -0.84 & 0.781 & 64 & 1.3 & 0.23 \\
\hline 113.140 & $4-4-5-3-4-7-11-6$ & 664073777777600 & -0.424 & -2.089 & 1.241 & 26 & 1.2 & 0.38 \\
\hline 92.666 & $3-4-5-3-4-6-11-5$ & 664073777741600 & -0.351 & -1.389 & 0.687 & 30 & 1.2 & 0.53 \\
\hline 73.140 & $4-4-5-3-4-6-11-7$ & 664073777777600 & -0.619 & -1.374 & 0.136 & 24 & 1.1 & 0.23 \\
\hline 34.668 & $4-4-5-3-4-7-9-7$ & 664073777707600 & -0.095 & -1.849 & 1.659 & 12 & 1.1 & 0.33 \\
\hline 17.142 & $4-4-2-3-3-7-11-7$ & 664073777763600 & 0.005 & -0.995 & 1.005 & 54 & 1.1 & 0.19 \\
\hline 72.140 & $4-4-5-3-4-7-10-8$ & 664073777777600 & 0.337 & -1.077 & 1.75 & 54 & 1.1 & 0.37 \\
\hline 18.129 & $3-4-5-2-4-6-9-8$ & 676473777777600 & 0.45 & -0.487 & 1.387 & 56 & 1 & 0.33 \\
\hline 23.142 & $4-4-2-3-3-5-11-7$ & 664073777763600 & 1.08 & -0.718 & 2.877 & 42 & 1 & 0.14 \\
\hline
\end{tabular}




\begin{tabular}{|c|c|c|c|c|c|c|c|c|}
\hline 27.140 & $4-4-5-2-3-5-10-7$ & 664073777777600 & -0.308 & -1.935 & 1.32 & 53 & 0.9 & 0.40 \\
\hline 122.263 & $4-4-4-1-4-6-10-7$ & 664073774037600 & 0.691 & -1.098 & 2.481 & 37 & 0.9 & 0.21 \\
\hline 49.140 & $4-2-5-3-4-7-11-8$ & 664073777777600 & -0.65 & -1.47 & 0.17 & 58 & 0.8 & 0.16 \\
\hline 16.273 & $4-3-4-3-2-7-6-8$ & 664073777777200 & 0.447 & -1.606 & 2.5 & 57 & 0.8 & 0.25 \\
\hline 103.142 & $4-4-3-3-3-7-11-7$ & 664073777763600 & 0.082 & -2.71 & 2.874 & 30 & 0.7 & 0.27 \\
\hline 10.140 & $3-4-5-3-4-7-11-9$ & 664073777777600 & 0.121 & -1.251 & 1.494 & 60 & 0.7 & 0.29 \\
\hline 106.140 & $2-4-5-1-4-6-10-9$ & 664073777777600 & -0.874 & -3.906 & 2.159 & 13 & 0.6 & 0.43 \\
\hline 45.140 & $3-4-5-2-3-5-10-7$ & 664073777777600 & 0.253 & -3.217 & 3.723 & 17 & 0.6 & 0.33 \\
\hline 2.140 & $4-4-5-3-3-7-11-7$ & 664073777777600 & 0.344 & -1.775 & 2.463 & 25 & 0.6 & 0.22 \\
\hline 53.142 & $4-4-5-3-3-7-11-9$ & 664073777763600 & 0.532 & -1.275 & 2.338 & 22 & 0.6 & 0.13 \\
\hline 20.131 & $4-4-5-3-4-5-11-9$ & 656573777777600 & -3.089 & -6.964 & 0.787 & 30 & 0.5 & 0.55 \\
\hline 87.140 & $3-4-5-2-3-4-10-7$ & 664073777777600 & 0.134 & -3.446 & 3.715 & 37 & 0.5 & 0.34 \\
\hline 56.140 & $4-4-5-3-4-7-10-7$ & 664073777777600 & 0.365 & -1.289 & 2.018 & 31 & 0.5 & 0.38 \\
\hline 120.140 & $4-2-5-2-4-7-11-7$ & 664073777777600 & -4.831 & -13.77 & 4.109 & 15 & 0.4 & 0.44 \\
\hline 107.140 & $4-2-3-3-4-7-11-7$ & 664073777777600 & 1.263 & -3.155 & 5.681 & 16 & 0.4 & 0.07 \\
\hline 24.2030 & $3-3-4-2-2-7-11-7$ & 676573757017600 & 13.718 & -20.189 & 47.624 & 3 & 0.4 & 1.00 \\
\hline 147.140 & $5-2-5-3-4-6-11-7$ & 664073777777600 & -5.47 & -14.285 & 3.345 & 11 & 0.3 & 0.27 \\
\hline 44.142 & $4-4-5-3-3-6-11-7$ & 664073777763600 & -5.024 & -17.326 & 7.279 & 21 & 0.3 & 0.17 \\
\hline 201.273 & $4-4-4-3-2-7-6-10$ & 664073777777200 & -3.271 & -14.56 & 8.018 & 13 & 0.3 & 0.07 \\
\hline 3.975 & $4-4-5-1-4-6-10-7$ & 640000037777600 & -2.49 & -7.691 & 2.71 & 42 & 0.3 & 0.36 \\
\hline 29.140 & $3-2-5-3-4-7-10-7$ & 664073777777600 & 2.004 & -7.439 & 11.447 & 15 & 0.3 & 0.36 \\
\hline 123.140 & $4-4-5-3-5-7-11-7$ & 664073777777600 & 2.128 & -9.278 & 13.535 & 11 & 0.3 & 0.19 \\
\hline 206.140 & $6-4-5-1-4-6-10-9$ & 664073777777600 & 4.502 & -1.537 & 10.54 & 16 & 0.3 & 0.04 \\
\hline 4.273 & $4-4-5-3-4-7-11-7$ & 664073777777200 & 4.589 & -3.909 & 13.087 & 23 & 0.3 & 0.38 \\
\hline 22.142 & $4-4-5-3-3-7-11-6$ & 664073777763600 & -4.614 & -12.462 & 3.234 & 20 & 0.2 & 0.36 \\
\hline 52.142 & $4-3-5-3-3-7-11-7$ & 664073777763600 & 3.921 & -2.495 & 10.338 & 17 & 0.2 & 0.13 \\
\hline 12.140 & $3-4-4-3-4-9-11-10$ & 664073777777600 & 4.205 & -9.414 & 17.824 & 17 & 0.2 & 0.50 \\
\hline 33.140 & $4-4-5-3-4-7-11-10$ & 664073777777600 & 4.506 & -13.573 & 22.586 & 17 & 0.2 & 0.11 \\
\hline 297.263 & $3-4-4-1-4-7-10-7$ & 664073774037600 & -71.161 & -201.664 & 59.341 & 8 & 0.1 & 0.38 \\
\hline 5.1035 & $4-2-5-3-4-7-11-7$ & 664073777743600 & -7.295 & -51.897 & 37.307 & 18 & 0.1 & 0.08 \\
\hline 26.140 & $4-1-5-3-4-7-11-7$ & 664073777777600 & -2.485 & -48.236 & 43.265 & 4 & 0.1 & 0.75 \\
\hline 211.140 & $4-4-5-2-4-7-11-7$ & 664073777777600 & -1.858 & -31.479 & 27.763 & 11 & 0.1 & 0.31 \\
\hline 21.142 & $4-4-5-3-3-7-10-7$ & 664073777763600 & 5.094 & -10.506 & 20.694 & 15 & 0.1 & 0.29 \\
\hline 237.140 & $4-4-3-3-4-7-11-4$ & 664073777777600 & -35.981 & -222.983 & 151.02 & 6 & 0 & 0.02 \\
\hline 296.142 & $3-4-2-3-3-7-11-7$ & 664073777763600 & 18.068 & -53.737 & 89.873 & 8 & 0 & 0.08 \\
\hline
\end{tabular}




\section{Figures}

Figure 1. Estimated skin test responses (mean at 24 months age and $95 \% \mathrm{Cls}$ ) of cattle infected with different genotypes of $M$. bovis. Estimates for female cattle shown, along with sample size for both sexes. Dotted line indicates overall mean response.

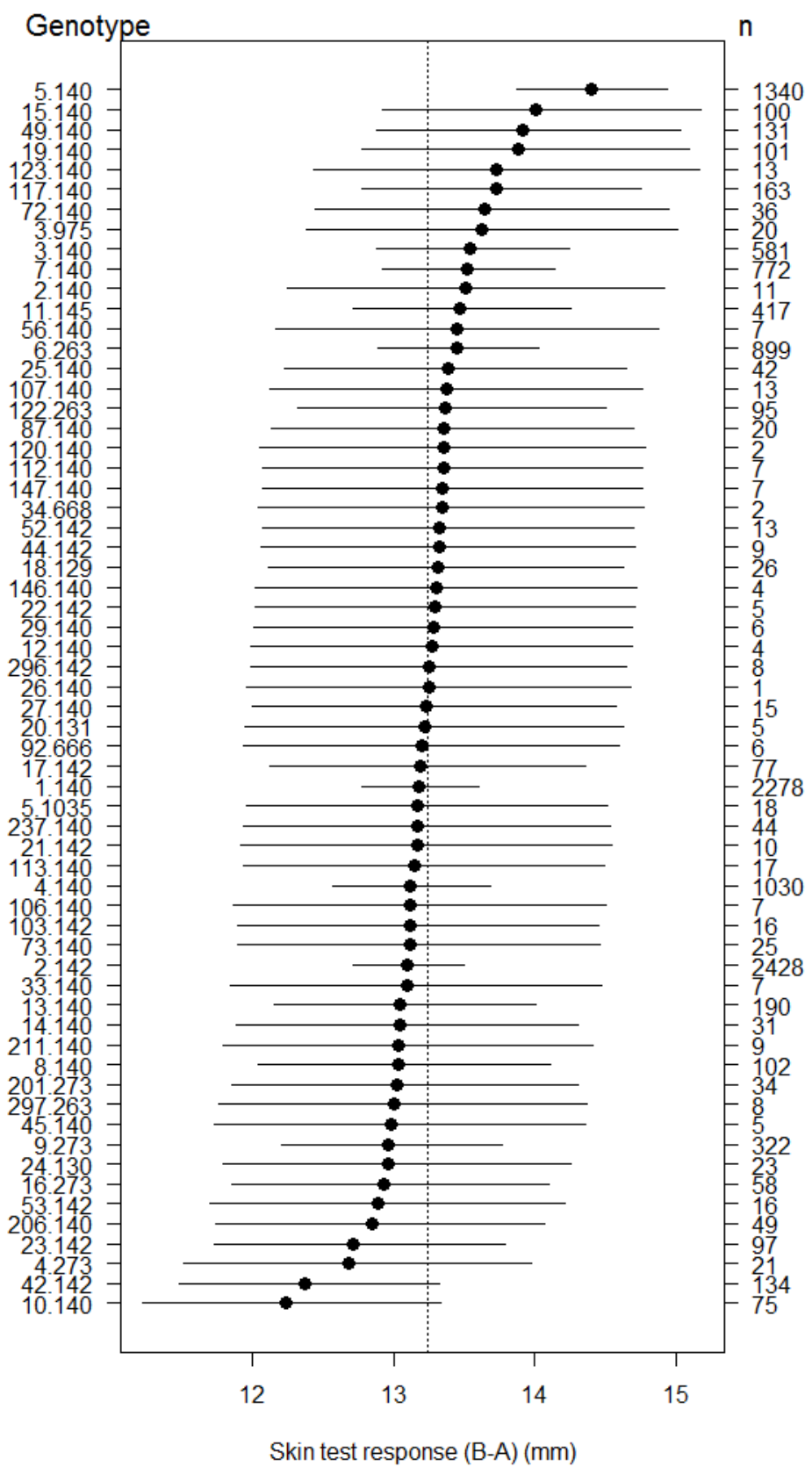


Figure 2. Estimated skin test responses (mean at 24 months age and $95 \% \mathrm{Cls}$ ) of different cattle breeds infected with $M$. bovis. Estimates for female cattle shown, along with sample size for both sexes. Only breeds with sample sizes greater than 10 are displayed. Dotted line indicates overall mean response. Breed codes: AA - Aberdeen Angus, AYR - Ayrshire, BB - Belgian Blue, CH Charolais, DAQ - Blonde D'Aquitaine, HER - Hereford, HOL - Holstein, JER - Jersey, LIM - Limousin, MB - Montbeliarde, MRI - Meuse Rhine Issel, SAL - Salers, SBR - Swiss Brown, SD - South Devon, SH - Shorthorn, SIM - Simmental.




Figure 3. Distribution of a) skin test detection ratios and b) reactor incidence rates across catchments of twelve abattoirs in Northern Ireland. All abattoirs were sampled over eight years except A, B and E ( $n=6,4$ and 1 respectively). Whiskers indicate range of data, box boundaries indicate upper and lower quartiles, solid line indicates median.
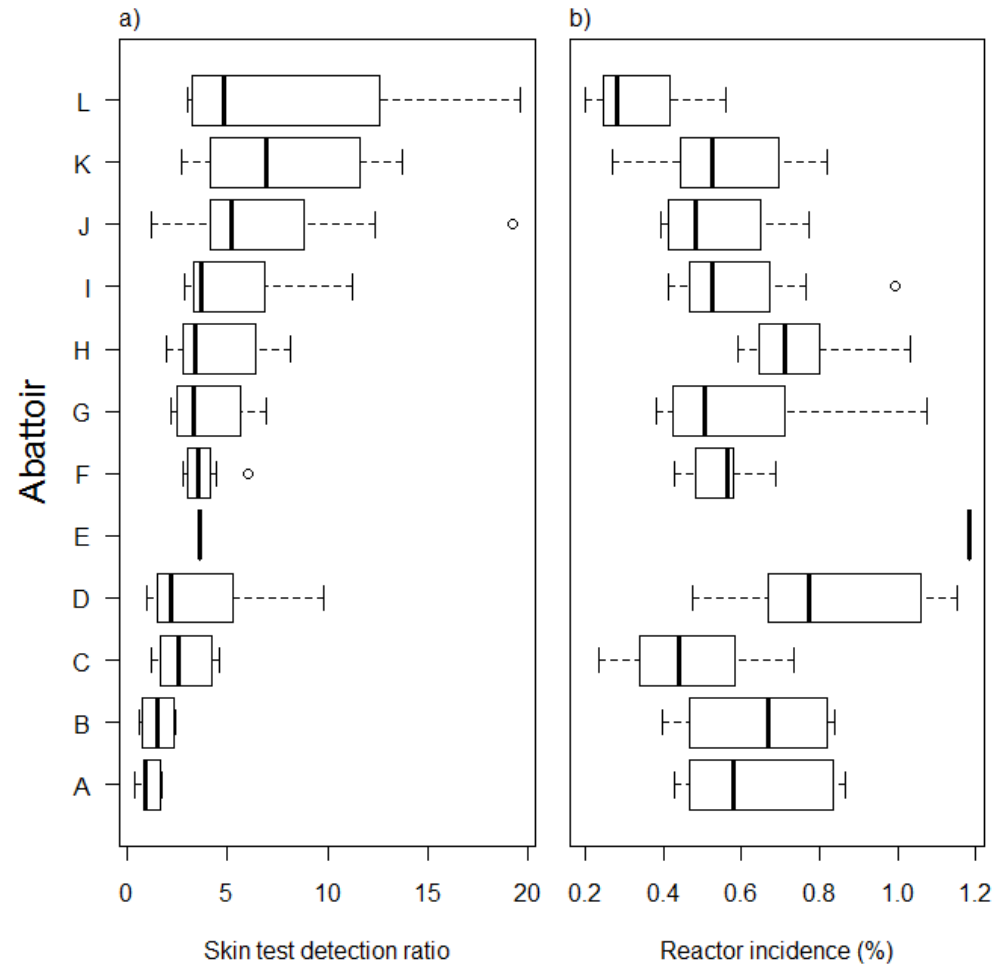